\title{
Comparison of nebulised salbutamol and ipratropium bromide with salbutamol alone in the treatment of chronic obstructive pulmonary disease
}

\author{
P Moayyedi, J Congleton, R L Page, S B Pearson, M F Muers
}

\begin{abstract}
Background - Patients admitted with acute exacerbation of chronic obstructive pulmonary disease (COPD) are often prescribed ipratropium bromide in combination with a $\beta_{2}$ agonist such as salbutamol. Studies have not shown any benefit in adding ipratropium bromide to salbutamol in acute exacerbations of COPD, but these studies have only assessed patients for 60-90 minutes and short term studies may not predict long term clinical response. Combination therapy with the two drugs was compared with salbutamol alone in the treatment of acute exacerbations of COPD during a hospital admission.
\end{abstract}

Methods - Seventy patients admitted to hospital with an acute exacerbation of COPD were randomly allocated to receive either nebulised salbutamol $5 \mathrm{mg}$ and ipratropium bromide $500 \mu \mathrm{g}$, or nebulised salbutamol $5 \mathrm{mg}$ alone (all four times a day) on admission. All other treatment was prescribed at the discretion of the attending physician. Length of stay in hospital and spirometeric values on days 1,3 , 7, 14, and discharge were assessed. Patients completed a subjective symptom score each day.

Results - There was no difference between the two groups in the mean (SD) length of stay (salbutamol 10.5 (4.7) days, salbutamol + ipratropium bromide 11.8 (4.4) days; $95 \%$ CI -1.02 to 3.62 ). There was no difference in spirometric values on days 1 , $3,7,14$, or discharge between the two groups. The subjective improvement was similar with both treatments.

Conclusions - The routine addition of nebulised ipratropium bromide to salbutamol appears to be of no benefit in the treatment of acute exacerbations of COPD.

(Thorax 1995;50:834-837)

Keywords: chronic obstructive pulmonary disease, $\beta_{2}$ agonist, ipratropium bromide.

Patients admitted to hospital with an acute exacerbation of chronic obstructive pulmonary disease (COPD) are usually treated with a high dose $\beta_{2}$ agonist as part of their therapy. It is now commonplace for patients to receive, in addition, nebulised ipratropium bromide with obvious additional cost. This is logical pharmacologically as ipratropium has a different mode of action, inhibiting vagally-mediated bronchomotor tone. ${ }^{1}$ There is evidence that adding ipratropium bromide to a nebulised $\beta_{2}$ agonist is valuable in the long term management of $\mathrm{COPD}^{2-4}$ and in acute severe asthma. ${ }^{5}$ There have been no studies, however, on the place of ipratropium bromide in the management of acute exacerbations of COPD. Additionally, it has been known for some years that atropine-like drugs may be more effective in remissions of airways obstruction than in relapse ${ }^{67}$ We have therefore compared nebulised salbutamol with nebulised salbutamol plus ipratropium bromide (combination therapy) in the treatment of acute exacerbations of COPD in a randomised trial.

\section{Methods}

Patients admitted as emergencies to acute medical units with a diagnosis of an acute exacerbation of COPD who were not taking regular nebulised bronchodilators at home were eligible for the study. All were aged over 45 years and had a smoking history of more than 10 pack years. All had a forced expiratory volume in one second $\left(\mathrm{FEV}_{1}\right)$ of $<65 \%$ predicted when well, and a history of exertional dyspnoea resulting from respiratory disease for over three years. The diagnosis of non-asthmatic COPD was made previously by a consultant respiratory physician. Exclusion criteria included a history suggestive of asthma (childhood respiratory disease, atopy, night time wheezing) and a peripheral eosinophilia of $>10 \%$. Patients with a $>20 \%$ (at least $200 \mathrm{ml}$ ) reversibility of $\mathrm{FEV}_{1}$ to $400 \mu \mathrm{g}$ of inhaled salbutamol on the day of discharge were also excluded.

On admission patients were randomised to receive either nebulised salbutamol $5 \mathrm{mg}$ four times daily or salbutamol $5 \mathrm{mg}$ plus ipratropium bromide $500 \mu \mathrm{g}$ four times daily. The drugs were administered by an air driven nebuliser (Bard Inspiron Mini-Neb) at a flow rate of $81 / \mathrm{min}$ until the chamber was dry. The combination therapy was given as a mixture. All other medication was prescribed at the attending physician's discretion.

Spirometric values (best of three attempts using a Vitalograph dry wedge spirometer by one of two experienced operators) were measured before the 18.00 hours nebuliser treat- 
How is your shortness of breath today compared with yesterday?

$\begin{array}{lr}\text { Better } & +1 \\ \text { Same } & 0 \\ \text { Worse } & -1\end{array}$

Please put the appropriate number next to each day.

$$
\begin{aligned}
& \text { Day } 1 \\
& 2 \\
& 3 \\
& 4 \\
& 5 \\
& 6 \\
& 7 \\
& \text {. . etc }
\end{aligned}
$$

Figure 1 Subjective symptom assessment.

ment on days $1,3,7$, and then weekly and on the day of discharge. Thus, patients admitted before 18.00 hours had spirometric parameters measured on the day of admission whilst those admitted after this time were measured at $\mathbf{1 8 . 0 0}$ hours the following day (all classified as day 1). In all cases the time of admission was noted. A simple subjective symptom score (fig 1) was recorded daily. The patients were asked whether they felt better, worse, or the same as the previous day.

The change in $\mathrm{FEV}_{1}$ and forced vital capacity (FVC) from day 1 to days 3, 7, 14, and day of discharge was calculated. The differences between each treatment group and the symptom scores were analysed by the Student's unpaired $t$ test. The sample size in this study would detect a $280 \mathrm{ml}$ change in $\mathrm{FEV}_{1}$ and $500 \mathrm{ml}$ change in FVC with $80 \%$ power and 95\% confidence.

Verbal consent was obtained from all patients. The study was approved by the clinical research ethics committees of the two health districts involved. Patients were blind to the medication they received, and the doctors who performed the spirometric measurements were not aware of the treatment group of each patient.

\section{Results}

Seventy patients entered the study. Three withdrew (one from the salbutamol group and two from the combination group), two were excluded as they had reversibility of $>20 \%$ (one from each group), and one patient from the salbutamol group was withdrawn as the reason for admission was newly diagnosed bronchial carcinoma. Two patients were withdrawn due to side effects of the nebulised drugs; one from the salbutamol only group developed chest pain and one in the combination therapy group developed wheezing which resolved on discontinuation of ipratropium. The remaining 62 patients were suitable for analysis. Three patients died during the course of their admission, one in the salbutamol group and two receiving combination therapy. Two patients prescribed ipratropium developed urinary obstruction but this did not necessitate their withdrawal from the study. Table 1 shows the baseline characteristics of the two treatment groups. The patients were well matched for all the parameters (Student's unpaired $t$ test). Day 1 spirometric values were always measured at 18.00 hours and therefore at a variable time from admission, but always within 24 hours. There was, however, no difference in the time of admission between the two groups (table 1).

The length of hospital stay and duration of nebuliser therapy was similar in both groups. There was no significant difference in the quantity of intravenous hydrocortisone, aminophylline and oral antibiotics received by the two groups (table 2).

Patient progress was monitored by $\mathrm{FEV}_{1}$ and

\begin{tabular}{|c|c|c|c|c|}
\hline & $S(n=33)$ & $S+I B(n=29)$ & $p$ & $95 \%$ CI of difference \\
\hline $\begin{array}{l}\text { Age (years) } \\
\text { Height }(\mathrm{cm}) \\
\text { Weight }(\mathrm{kg}) \\
\text { Years breathless } \\
\text { Smoking (pack years) } \\
\mathrm{PaO}_{2}{ }^{*}(\mathrm{kPa}) \\
\mathrm{PaCO}_{2}{ }^{*}(\mathrm{kPa}) \\
\mathrm{Time} \text { of admission } \\
\text { FEV }_{1} \text { day } 1 \text { (1) } \\
\text { FVC day } 1 \text { (1) }\end{array}$ & $\begin{array}{c}70.4(9.1) \\
163.8(9 \cdot 7) \\
65.0(16.9) \\
10.6(11 \cdot 3) \\
48.8(32 \cdot 3) \\
8.5(2 \cdot 4) \\
5.4(1.3) \\
13.40(5.0) \\
0.77(0.34) \\
1.47(0.65)\end{array}$ & $\begin{array}{c}67 \cdot 8(6 \cdot 7) \\
165 \cdot 0(9 \cdot 6) \\
65 \cdot 3(15 \cdot 7) \\
16.5(12 \cdot 9) \\
55 \cdot 0(32 \cdot 1) \\
7 \cdot 8(1 \cdot 6) \\
5.9(1.5) \\
12.50(5 \cdot 0) \\
0.78(0 \cdot 41) \\
1.55(0 \cdot 71)\end{array}$ & $\begin{array}{l}\text { NS } \\
\text { NS } \\
\text { NS } \\
\text { NS } \\
\text { NS } \\
\text { NS } \\
\text { NS } \\
\text { NS } \\
\text { NS } \\
\text { NS }\end{array}$ & $\begin{array}{r}-6.71 \text { to } 1.51 \\
-3.71 \text { to } 6.11 \\
-8.02 \text { to } 8.62 \\
-0.25 \text { to } 12.04 \\
-10.20 \text { to } 22.60 \\
-1.75 \text { to } 0.35 \\
-0.21 \text { to } 1.21 \\
-3.38 \text { to } 1.71 \\
-0.18 \text { to } 0.20 \\
-0.27 \text { to } 0.43\end{array}$ \\
\hline
\end{tabular}
FVC (figs 2 and 3) and the change in these parameters between days $1,3,7,14$, and discharge was calculated. There was no significant

Table 1 Mean (SD) baseline characteristics of the two treatment groups

\begin{tabular}{|c|c|c|c|c|}
\hline & $S(n=33)$ & $S+I B(n=29)$ & $p$ & $95 \%$ CI of difference \\
\hline $\begin{array}{l}\text { Days to discharge } \\
\text { Days on nebulisers } \\
\text { Days on iv aminophylline } \\
\text { Days on iv steroids } \\
\text { Days on antibiotics }\end{array}$ & $\begin{array}{r}10 \cdot 5(4 \cdot 7) \\
8 \cdot 5(4 \cdot 2) \\
0 \cdot 1(0 \cdot 5) \\
0 \cdot 1(0 \cdot 3) \\
5 \cdot 8(4 \cdot 3)\end{array}$ & $\begin{aligned} 11.8(4.4) \\
8 \cdot 2(3 \cdot 6) \\
0.6(1.4) \\
0.6(1.4) \\
5 \cdot 7(3.3)\end{aligned}$ & $\begin{array}{l}\text { NS } \\
\text { NS } \\
\text { NS } \\
0 \cdot 05 \\
\text { NS }\end{array}$ & $\begin{array}{l}-1.02 \text { to } 3.62 \\
-2.30 \text { to } 1.70 \\
-0.02 \text { to } 1.02 \\
-0.005 \text { to } 1.0 \\
-2.07 \text { to } 1.87\end{array}$ \\
\hline
\end{tabular}

$\mathrm{S}=$ salbutamol alone; $\mathrm{S}+\mathrm{IB}=$ combination therapy; $\mathrm{PaO}_{2}, \mathrm{PaCO}_{2}=$ arterial oxygen and carbon dioxide tensions; $\mathrm{FEV}=$ forced expiratory volume in one second; $\mathrm{FVC}=$ forced vital capacity. * On admission.

Table 2 Mean (SD) length of hospital stay and drug therapy of the two treatment groups 
Table 3 Mean (SD) changes in forced expiratory volume in one second (FEV $)$ and forced vital capacity (FVC) over time

\begin{tabular}{|c|c|c|c|c|}
\hline & $S(n=33)$ & $S+I B(n=29)$ & $p$ & $95 \%$ CI of difference \\
\hline $\begin{array}{l}\mathrm{FEV}_{1} \\
\text { Day } 3 \text {-Day } 1 \\
\text { Day } 7 \text {-Day } 1 \\
\text { Day } 14 \text {-Day } 1 \\
\text { Day of discharge - Day } 1\end{array}$ & $\begin{array}{l}0.17(0.28) \\
0.21(0.42) \\
0.06(0.11) \dagger \\
0.23(0.32)\end{array}$ & $\begin{array}{l}0.05(0.24) \\
0.15(0.26) \\
0.26(0.29)^{*} \\
0.15(0.32)\end{array}$ & $\begin{array}{l}\text { NS } \\
\text { NS } \\
\text { NS } \\
\text { NS }\end{array}$ & $\begin{array}{l}-0.25 \text { to } 1.34 \\
-0.24 \text { to } 0.12 \\
-0.02 \text { to } 0.42 \\
-0.24 \text { to } 0.08\end{array}$ \\
\hline $\begin{array}{l}\text { FVC } \\
\text { Day } 3-\text { Day } 1 \\
\text { Day } 7 \text {-Day } 1 \\
\text { Day } 14-\text { Day } 1 \\
\text { Day of discharge-Day } 1\end{array}$ & $\begin{array}{l}0.25(0.42) \\
0.39(0.52) \\
0.33(0.23) \dagger \\
0.56(0.47)\end{array}$ & $\begin{array}{l}0.04(0.41) \\
0.17(0.45) \\
0.62(0.51)^{*} \\
0.42(0.61)\end{array}$ & $\begin{array}{l}0 \cdot 05 \\
\text { NS } \\
\text { NS } \\
\text { NS }\end{array}$ & $\begin{array}{l}-0.42 \text { to } 0.001 \\
-0.47 \text { to } 0.03 \\
-0.10 \text { to } 0.68 \\
-0.41 \text { to } 0.13\end{array}$ \\
\hline
\end{tabular}

* 10 patients, +9 patients.

$S=$ salbutamol alone, $S+I B=$ combination therapy.

Table 4 Mean (SD) subjective improvement over hospital stay

\begin{tabular}{lllll}
\hline & $S(n=33)$ & $S+I B(n=29)$ & $p$ & $95 \%$ CI of difference \\
\hline Number of days better & $4.5(1 \cdot 8)$ & $4.8(2.4)$ & NS & -0.77 to 1.37 \\
Number of days same & $3.9(2 \cdot 8)$ & $4.7(2.7)$ & NS & -0.60 to 2.20 \\
Number of days worse & $1.2(1 \cdot 4)$ & $1.3(1.5)$ & NS & -0.64 to 0.84 \\
\hline
\end{tabular}

$\mathrm{S}=$ salbutamol alone; $\mathrm{S}+\mathrm{IB}=$ combination therapy.

difference between the two groups (table 3), and no difference was observed in the subjective improvement between the two groups (table 4).

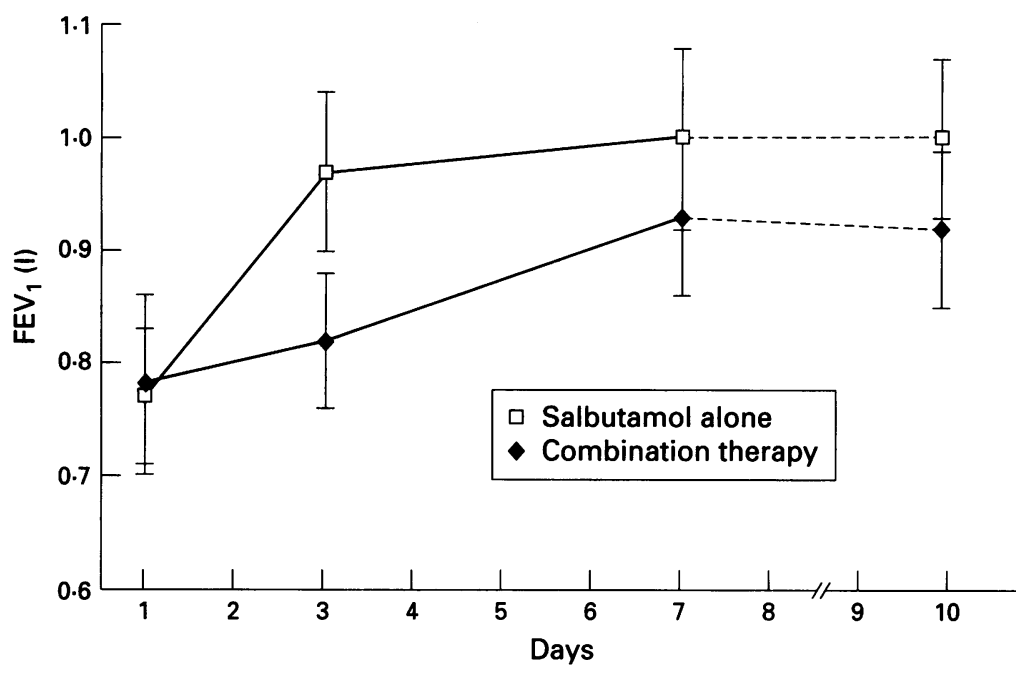

Figure 2 Mean (SE) FEV over admission.

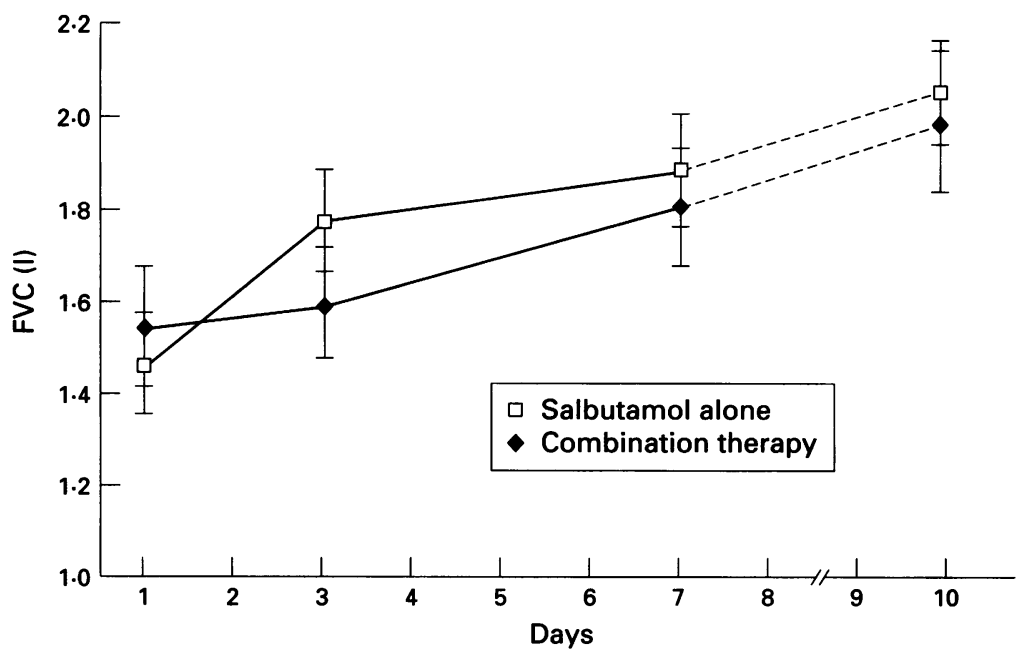

Figure 3 Mean (SE) FVC over admission.

\section{Discussion}

The combination of salbutamol and ipratropium bromide appeared to give no additional benefit compared with salbutamol alone during the routine inpatient treatment of an acute exacerbation of COPD. No differences were observed in spirometric values, subjective symptom scores, duration of hospital stay, or number of days on a nebuliser between the two groups. This is in contrast to findings in stable COPD although results are not consistent. Many trials in stable outpatients with COPD have shown combination therapy to be beneficial, ${ }^{8-12}$ although some suggest that any improvement is small. ${ }^{91314}$ Furthermore, some workers have shown that ipratropium bromide alone is as effective as either salbutamol alone or combination therapy. ${ }^{15-17}$

There are far fewer studies on acute exacerbations of COPD. In a study by O'Driscoll et $a l^{2}$ combination therapy provided no additional benefit to single agent therapy in the first hour. An earlier study ${ }^{18}$ found that either fenoterol or ipratropium bromide was as effective as the two agents combined in producing bronchodilation over a 90 minute period. These studies have assessed patients with acute exacerbations of COPD over 60-90 minutes, but short term reversibility alone cannot be relied upon to predict longer term clinical response. ${ }^{19-21}$ In assessing therapy it is important to monitor patients with acute exacerbations of COPD throughout a hospital admission and, to our knowledge, this is the first study which compares the use of salbutamol alone with combination therapy for this duration.

It is possible that this study did not have a sufficiently large sample size to detect a small improvement in spirometric values by the addition of ipratropium bromide. This study would detect a difference in mean $\mathrm{FEV}_{1}$ of $280 \mathrm{ml}$ at each point with $80 \%$ power and we feel that a difference of less than this magnitude is of doubtful clinical significance. We consider that the dose of ipratropium bromide used was sufficient because a previous study has shown that $500 \mu \mathrm{g}$ is in excess of that required to 
achieve maximal acute reversibility in stable COPD. ${ }^{22}$

As in other studies, we considered changes in $\mathrm{FEV}_{1}$ and FVC to be more objective than serial peak flow measurements in measuring bronchodilation. It is well recognised that there is only limited correlation between spirometric values and subjective sensations of dyspnoea and exercise tolerance in COPD. ${ }^{23-25}$ There are a number of validated multidimensional questionnaires to assess wellbeing in patients with COPD. ${ }^{26}$ These, however, have mainly been used in patients with stable COPD and the few questionnaires designed to respond to rapid changes in disease activity are time consuming to complete. ${ }^{27} \mathrm{We}$ therefore confined ourselves to a single measure of subjective benefit similar to that used in other studies assessing nebuliser therapy. ${ }^{28}$

Although ipratropium bromide is generally well tolerated and safe, adverse (anticholinergic) effects do occur. The addition of ipratropium bromide to a $\beta_{2}$ agonist in the treatment of acute COPD will therefore increase the possibility of side effects as well as the cost of therapy.

We conclude that the addition of ipratropium to salbutamol confers no benefit in the routine management of hospital inpatients with acute exacerbations of COPD. We consider that these results apply only to acute exacerbations and the situation with respect to long term domiciliary treatment is different. In the treatment of an acute exacerbation of COPD it would seem reasonable to advise adding nebulised ipratropium bromide to a $\beta_{2}$ agonist only when a patient is not progressing satisfactorily. This is now our unit policy.

We are grateful to Wanda Macdonald and Rosemary Bunting for their help with spirometery and Dr J M Findlay for his permission to study patients at the Bradford Royal Infirmary. We also thank Dr David Braunholtz for his statistical advice.

1 Gross NJ, Skorodin MS. Anticholinergic, antimuscarinic bronchodilators. Am Rev Respir Dis 1984;129:856-70.

2 O'Driscoll BR, Horsley MG, Taylor RJ, Chambers DK Bernstein A. Nebulised salbutamol with and without ipratropium bromide in acute airflow obstruction. Lance 1989;i:1418-20.

3 Morrison JFJ, Jones PC, Muers MF. Assessing physiological benefit from domiciliary nebulized bronchodilators in severe airflow limitation. Eur Respir 7 1992;5:424-9.

4 Goldman JM, Teale C, Muers MF. Simplifying the assessment of patients with chronic airflow limitation for home nebuliser therapy. Respir Med 1992;86:33-8.
5 Ward MF, Fentem PH, Roderick Smith WH, Davies D. Ipratropium bromide in acute asthma. $B M \mathcal{F} 1981 ; 282$ 598-600.

6 Altounyan REC. Variation of drug action on airway obstruction in man. Thorax 1964;19:406-15.

7 Teale C, Morrison JFJ, Muers MFM, Pearson SB. Response to nebulized ipratropium bromide and terbutaline in acute to nebulized ipratropium bromide and terbuta

8 Brown IG, Chan CS, Kelly CA, Dent AG, Zimmerman PV. Assessment of the clinical usefulness of nebulised ipratropium bromide in patients with chronic airflow limitation. Thorax 1984;39:272-6.

9 Hughes JA, Tobin MJ, Bellamy D, Hutchinson DCS. Effects of ipratropium bromide and fenoterol aerosols in pulmonary emphysema. Thorax 1982;37:667-70.

10 Gross NJ, Skorodin MS. Role of the parasympathetic system in airway obstruction due to emphysema. $N$ Engl $\Im \mathrm{Med}$ 1984;311:421-5.

11 Crane J, Gamble S, Purdie G. Comparison of a fenoterol/ ipratropium combination with salbutamol form metered dose inhalers in subjects with chronic partially reversible airways obstruction. NZ Med $\mathcal{f} 1987 ; 100: 385-7$.

12 Rudolf $M$. Combination therapy - a review of clinical studies. Postgrad Med $\mathcal{f}$ 1984;60:(Suppl) 9-12.

13 Duovent - is logic enough? Drug Ther Bull 1985;23:3-4.

14 Connolly CK, Chan NS. Salbutamol and ipratropium in partially reversible airway obstruction. Brf Dis Chest 1987; 81:55-61.

15 Braun SR, McKenzie WJ, Copeland C, Knight L, Ellersieck $M$. A comparison of the effect of ipratropium and albuterol in the treatment of chronic obstructive airways disease. Arch Intern Med 1989;149:544-7.

16 Easton PA, Jadue C, Dhingra S, Anthonisen NR. A comparison of the bronchodilating effects of a beta-2 adrenergic agent (albeterol) and an anticholinergic agent (ipratropium bromide), given by aerosol alone or in se(ipratropium bromide), given by aeroso

17 Karpel JP. Bronchodilator response to anticholinergic and beta-adrenergic agents in acute and stable COPD. Chest beta-adrenergic

18 Rebuck AS, Chapman KR, Abboud R, Pare PD, Kreisman $\mathrm{H}$, Wolkove $\mathrm{N}$, et al. Nebulized airways disease in the emergency room. Am $\mathcal{f}$ Med 1987;82:59-64.

19 Pratter MR, Irwin RS. Predicting response to bronchodilator therapy in chronic obstructive pulmonary disease. Arch Intern Med 1988;148:1909-10.

20 Taylor DR, Buick B, Kinney C, Lowry RC, McDevitt DG. The efficacy of orally administered theophylline, inhaled salbutamol, and a combination of the two as chronic salbutaming and a combint of reversible airflow obstruction. Am Rev Respir Dis 1985; 131:747-51.

21 Teale C, Morrison JFJ, Jones PC, Muers MFM. Reversibility tests in chronic obstructive airways disease: their predictive value with reference to benefit from domiciliary nebulise therapy. Respir Med 1991;85:281-4.

22 Jenkins CR, Chow CM, Fisher BL, Marlin GE. Comparison of ipratropium bromide and salbutamol by aerosolized solution. Aust NZ $\mathcal{f}$ Med 1981;11:513-6.

23 Mahler DA, Weinberg DH, Wells CK, Feinstein AR. The measurement of dyspnea. Chest 1985;85:751-8.

24 Pineda H, Haas F, Axen K, Haas A. Accuracy of pulmonary function tests in predicting exercise tolerance in chronic obstructive pulmonary disease. Chest 1984;86:564-7.

25 Levy SF. Bronchodilators in COPD. To the max. Chest 1991;99:793.

26 Guyatt GH, Berman LB, Townsend M, Pugsley SO, Chambers LW. A measure of quality life for clinical trials in chronic lung disease. Thorax 1987;42:773-8.

27 Jones PW, Quirk FH, Baveystock CM, Littlejohns P. A selfcomplete measure of health status for chronic airflow limitation. The St George's Respiratory Questionnaire. Am Rev Respir Dis 1992;145:1321-7.

28 O'Driscoll BR, Kay EA, Taylor RJ, Weatherby H, Chetty MCP, Bernstein A. A longterm prospective assessment of home nebuliser treatment. Respir Med 1992;86:317-25. 